\title{
The effect of non-starch polysaccharide supplementation on circulating bile acids, hormone and metabolite levels following a fat meal in human subjects
}

\author{
BY L. M. MORGAN, J. A. TREDGER, Y. SHAVILA, J. S. TRAVIS \\ AND J. WRIGHT \\ School of Biological Sciences, University of Surrey, Guildford, Surrey GU2 5XH
}

(Received 22 May 1992 - Accepted 3 October 1992)

\begin{abstract}
The effects of guar gum, sugar-beet fibre (SBF) and wheat bran supplementation of a high-fat test meal were compared with an NSP-free control meal and a meal containing an equivalent amount of the ionexchange resin cholestyramine in healthy non-obese human volunteers. Their effects on gastric emptying, postprandial circulating bile acids, triacylglycerols and gastrointestinal hormone levels were studied. The in vitro binding of NSP and cholestyramine to $\left[1-{ }^{14} \mathrm{C}\right]$ glycocholic acid was measured and compared with their in vivo effect. Guar gum and cholestyramine supplementation significantly lowered circulating postprandial bile acid, triacylglycerol and gastric inhibitory polypeptide concentrations, but sugar-beet fibre and wheat bran were without effect. Liquid gastric emptying, as assessed by circulating paracetamol levels, was slightly accelerated in the guar gum-supplemented meal. Glycocholic acid bound strongly to the insoluble fraction of cholestyramine and the soluble fraction of guar gum. The insoluble fractions of SBF and wheat bran bound only small quantities of glycocholate; no bile acid binding was detected in the soluble fractions of these NSP. The study demonstrates that measurement of postprandial bile acids enables an indirect measurement to be made of bile acid binding to NSP in vivo. The results support the hypothesis that the hypocholesterolaemic action of guar gum is largely mediated via interruption of the enterohepatic bile acid circulation, but indicate that the hypocholesterolaemic action of SBF is mediated by another mechanism.
\end{abstract}

Bile acid: Gastric inhibitory polypeptide: Cholesterol: Non-starch polysaccharides: Humans

Elevated serum cholesterol levels have been identified as a risk factor for coronary heart disease (Betteridge, 1989). A number of studies have indicated that a high dietary intake of certain non-starch polysaccharides (NSP) can lower circulating cholesterol levels in man. Preparations with a high soluble NSP content are particularly effective. Two such preparations, guar gum, a soluble galactomannan, and sugar-beet fibre, which contains approximately $400 \mathrm{~g}$ soluble $\mathrm{NSP} / \mathrm{kg}$ in the form of pectic substances and soluble hemicelluloses, have well-documented hypocholesterolaemic effects in normolipidaemic, hyperlipidaemic and diabetic subjects (Jenkins et al. 1975; Khan et al. 1981; Penagini et al. 1986; Hagander et al. 1988; Tredger et al. 1991), whereas wheat bran, which contains mixed insoluble NSP, is largely reported without hypocholesterolaemic effect (Jenkins et al. 1975; Farrell et al. 1978; Moore et al. 1985; Tredger et al. 1991). The mechanisms whereby NSP lowers cholesterol are not clear. There is evidence that certain NSP can bind to bile acids in the small intestine with consequent interruption of the enterohepatic bile acid circulation and loss of cholesterol from increased faecal bile acid excretion (Eastwood \& Hamilton, 1968; Story \& Kritchevsky, 1976). This is an attractive hypothesis, resembling that of the therapeutic bile acid sequestrants such as cholestyramine which lowers 
circulating cholesterol by this mechanism (Hashim \& van Itallie, 1965). There are, however, discrepancies between the in vivo hypocholesterolaemic effect of an individual NSP, in vitro bile acid binding and faecal sterol excretion in both animal and human studies (Bosaeus et al. 1986; Kritchevsky et al. 1986; Topping et al. 1990). These could be due to a number of factors including the animal model chosen, the source of NSP used and the in vitro conditions chosen for binding studies. Measurements of faecal bile acid binding in vivo are laborious to perform; an alternative and more convenient estimation of any interruption to the entero-hepatic axis by NSP might be possible by measurement of postprandial circulating bile acids.

The present study investigates three NSP sources, sugar-beet fibre (SBF), guar gum and wheat bran. We have recently studied their hypocholesterolaemic properties in human volunteers (Tredger et al. 1991). Preparations of NSP taken from the same source as this previous study have been incorporated into a high-fat meal. Their effects on gastric emptying, postprandial circulating bile acid, triacylglycerol and gastrointestinal hormone levels have been compared with an NSP-free control meal and a meal containing an equivalent amount of the ion-exchange resin cholestyramine used as a positive control in an attempt to elucidate further the hypocholesterolaemic action of soluble NSP. The in vitro binding of NSP and cholestyramine to radiolabelled bile acids has also been measured and compared with their in vivo effect on postprandial circulating bile acid and triacylglycerol levels.

\section{MATERIALS AND METHODS \\ Clinical studies}

Sixteen healthy adults (seven male, nine female) participated in the study. Their ages ranged from 18 to 43 (mean 24.4 (SD 7.0)) years and their mean body mass index was 20.9 (SD 1.5$) \mathrm{kg} / \mathrm{m}^{2}$. Each subject gave his/her informed consent and the study was approved by the Ethical Committees of the Royal Surrey County Hospital, Guildford and the University of Surrey. Customary nutrient intake was assessed by a 3 d diary record, using estimated weights. Subjects attended on three separate occasions after an overnight fast at least 1 week apart and were assigned to one of the supplementation experiments.

\section{Study A. Guar gum or cholestyramine supplementation}

Eight of the subjects were given three high-fat test meals in random order as detailed in Table 1. The meals included on one occasion $10 \mathrm{~g}$ guar gum $(800 \mathrm{~g} \mathrm{NSP} / \mathrm{kg}$; Rybar Laboratories, Amersham) and on another $10 \mathrm{~g}$ cholestyramine (Questran A; Bristol-Myers Co. Ltd, Cambridge). All components of the individual test meals were thoroughly mixed before consumption. Soluble paracetamol (Soluble Panadol; Wynpharm, Guildford), $1.5 \mathrm{~g}$ dissolved in $200 \mathrm{ml}$ water, was consumed simultaneously with the meals on each occasion and plasma paracetamol levels were measured as an index of liquid gastric emptying (Morgan et al. 1988). Venous blood samples were collected through an indwelling catheter inserted into an antecubital vein and kept patent with $0 \cdot 123 \mathrm{M}$-sodium citrate. Samples were collected whilst subjects were fasting at rest and at frequent intervals for $180 \mathrm{~min}$ from the start of the meal.

\section{Study B. SBF and wheat bran supplementation}

Eight of the subjects were given the test meal (Table 1) in random order either with or without $10 \mathrm{~g} \mathrm{SBF}$ ( $800 \mathrm{~g} \mathrm{NSP} / \mathrm{kg}$; Betafibre; British Sugar, Peterborough) or wheat bran ( $360 \mathrm{~g} \mathrm{NSP} / \mathrm{kg}$; Boots, Nottingham). Paracetamol (1.5 g) was taken with each meal and venous blood samples were collected as in the previous experiment. 
Table 1. Composition of the control meal consumed by subjects with and without fibre supplementation

\begin{tabular}{lccccc}
\hline \hline & Wt $(\mathrm{g})$ & Energy $(\mathrm{kJ})$ & Fat $(\mathrm{g})$ & Carbohydrate $(\mathrm{g})$ & Protein $(\mathrm{g})$ \\
\hline Double cream & 52 & 971 & $25 \cdot 1$ & $1 \cdot 0$ & 0.8 \\
Chocolate (plain) & 17 & 373 & $5 \cdot 0$ & $11 \cdot 0$ & 0.8 \\
Total & 69 & 1344 & $30 \cdot 1$ & $12 \cdot 0$ & 1.6 \\
\hline
\end{tabular}

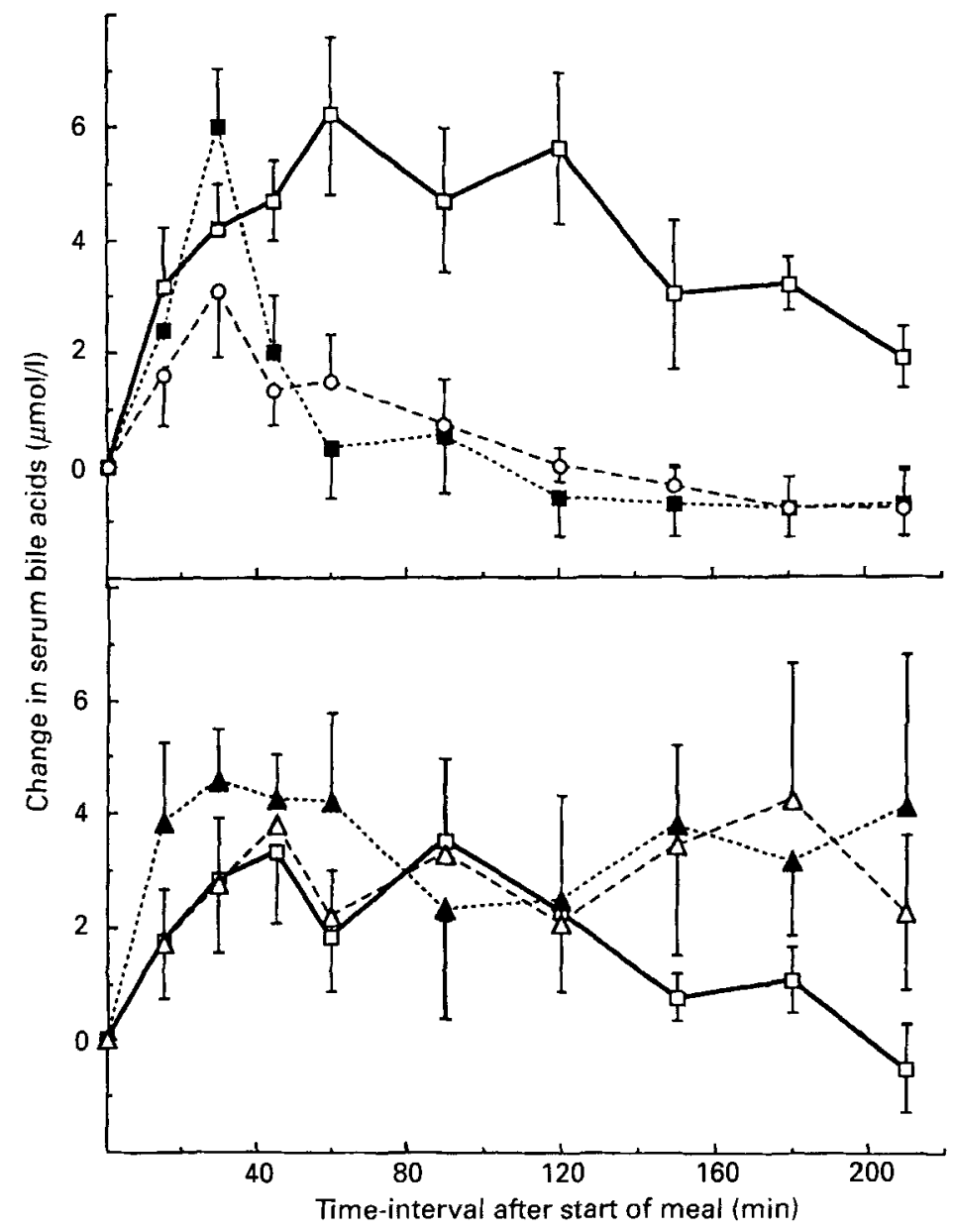

Fig. 1. Serum bile acid concentrations following a high-fat test meal alone ( $\square-\square$ ) or supplemented with $10 \mathrm{~g}$ guar gum ( $\boldsymbol{\square}-\mathbf{D})$, cholestyramine $(\mathrm{O}-\mathrm{O})$, sugar-beet fibre $(\Delta-\Delta)$ or wheat bran $(\boldsymbol{\Delta}-\boldsymbol{\Lambda})$ in eight healthy volunteers. Points are means with their standard errors represented by vertical bars. For details of procedures, see pp. $492-494$.

\section{Analyses}

Serum was analysed for total bile acids (Starkey \& Marks, 1982) and triacylglycerols (Wahlefield, 1974). Plasma was analysed for immunoreactive gastric inhibitory polypeptide (GIP; Morgan et al. 1978b) and paracetamol (Hallworth, 1983). Dietary records were 
Table 2. Effect of non-starch polysaccharides (NSP) and cholestyramine on incremental responses of plasma gastric inhibitory polypeptide (GIP), paracetamol, bile acids and triacylglycerols following oral fat in human subjects $\dagger$

(Mean values with their standard errors)

\begin{tabular}{|c|c|c|c|c|c|c|c|c|}
\hline & \multicolumn{8}{|c|}{ Incremental area under the curve, $0-210 \mathrm{~min}$} \\
\hline & \multicolumn{2}{|c|}{$\begin{array}{c}\text { GIP } \\
\text { (ng/l per h) }\end{array}$} & \multicolumn{2}{|c|}{$\begin{array}{l}\text { Paracetamol } \\
(\mu \mathrm{mol} / 1 \text { per h) }\end{array}$} & \multicolumn{2}{|c|}{$\begin{array}{c}\text { Bile acids } \\
(\mu \mathrm{mol} / 1 \text { per } \mathrm{h})\end{array}$} & \multicolumn{2}{|c|}{$\begin{array}{l}\text { Triacylglycerols } \\
(\mathrm{mmol} / 1 \text { per } \mathrm{h})\end{array}$} \\
\hline & Mean & SE & Mean & $\mathrm{SE}$ & Mean & $\mathrm{SE}$ & Mean & $\mathrm{SE}$ \\
\hline \multicolumn{9}{|l|}{ Study A } \\
\hline Control & 2542 & 317 & 362 & $25 \cdot 6$ & $13 \cdot 9$ & $1 \cdot 8$ & 0.94 & $0 \cdot 18$ \\
\hline Guar gum & $1360^{*}$ & 183 & 382 & $29 \cdot 1$ & $1 \cdot 7^{*}$ & $2 \cdot 2$ & $0.48^{*}$ & 0.20 \\
\hline Cholestyramine & $427^{*}$ & 129 & 335 & $27 \cdot 6$ & $1 \cdot 6^{*}$ & $1 \cdot 3$ & $0.07 *$ & $0 \cdot 34$ \\
\hline \multicolumn{9}{|l|}{ Study B } \\
\hline Control & 2121 & 360 & 274 & $26 \cdot 5$ & $6 \cdot 3$ & $2 \cdot 1$ & $1 \cdot 18$ & 0.23 \\
\hline Wheat bran & 1951 & 394 & 292 & $22 \cdot 4$ & $10 \cdot 8$ & $4 \cdot 1$ & 1.06 & $0 \cdot 31$ \\
\hline Sugar-beet fibre & 2040 & 319 & 293 & $13 \cdot 2$ & $10 \cdot 1$ & $4 \cdot 1$ & 1.50 & $0 \cdot 21$ \\
\hline
\end{tabular}

Mean values were significantly different from those for control test meals: $* P<0.01$.

$\dagger$ For details of procedures, see pp. 492494.

analysed using the Compeat computer program based on food composition tables (Paul \& Southgate, 1978).

\section{In vitro bile acid binding to NSP}

The in vitro binding of $\left[1-{ }^{14} \mathrm{C}\right]$ glycocholic acid to the insoluble fraction of NSP preparations and cholestyramine was measured on $100 \mathrm{mg}$ NSP or cholestyramine after Quin et al. (1991). The insoluble fibre fraction was separated by centrifugation at $2000 \mathrm{~g}$ for $30 \mathrm{~min}$. In vitro binding of $\left[1-{ }^{14} \mathrm{C}\right] \mathrm{glyc}$ cocholic acid to the soluble fraction of the NSP preparations was ascertained by submitting to ultracentrifugation $2 \mathrm{ml}$ of the supernatant fraction remaining after precipitation of the insoluble NSP fraction. A membrane with a cut-off of $10 \mathrm{kDa}$ (Centrisort I; Sartorius, Göttingen, Germany) was used and radioactivity was measured in a portion of the ultrafiltrate.

\section{Statistical analyses}

Repeated-measures analysis of variance (ANOVA) was used to detect differences in the postprandial circulating profiles of hormones and metabolites. Differences in total postprandial hormone and metabolite concentrations over the study period were detected by one-way ANOVA of the area under the curve (AUC), calculated using the trapezoidal rule. A Bartlett-Box $F$ test was employed to test for homoscedicity of data. Correlation coefficients followed by linear regression analysis were used to determine any relationship between subjects' customary dietary intake and postprandial hormone and metabolic responses. Data analysis was carried out using the SSPS information analysis system.

RESULTS

\section{Study A. Guar gum and cholestyramine supplementation}

Analysis of variance demonstrated a significant effect of guar gum and cholestyramine supplementation on the postprandial circulating total bile acid, triacylglycerol, GIP and paracetamol curves in comparison with the unsupplemented control meal $(P<0.01)$. 


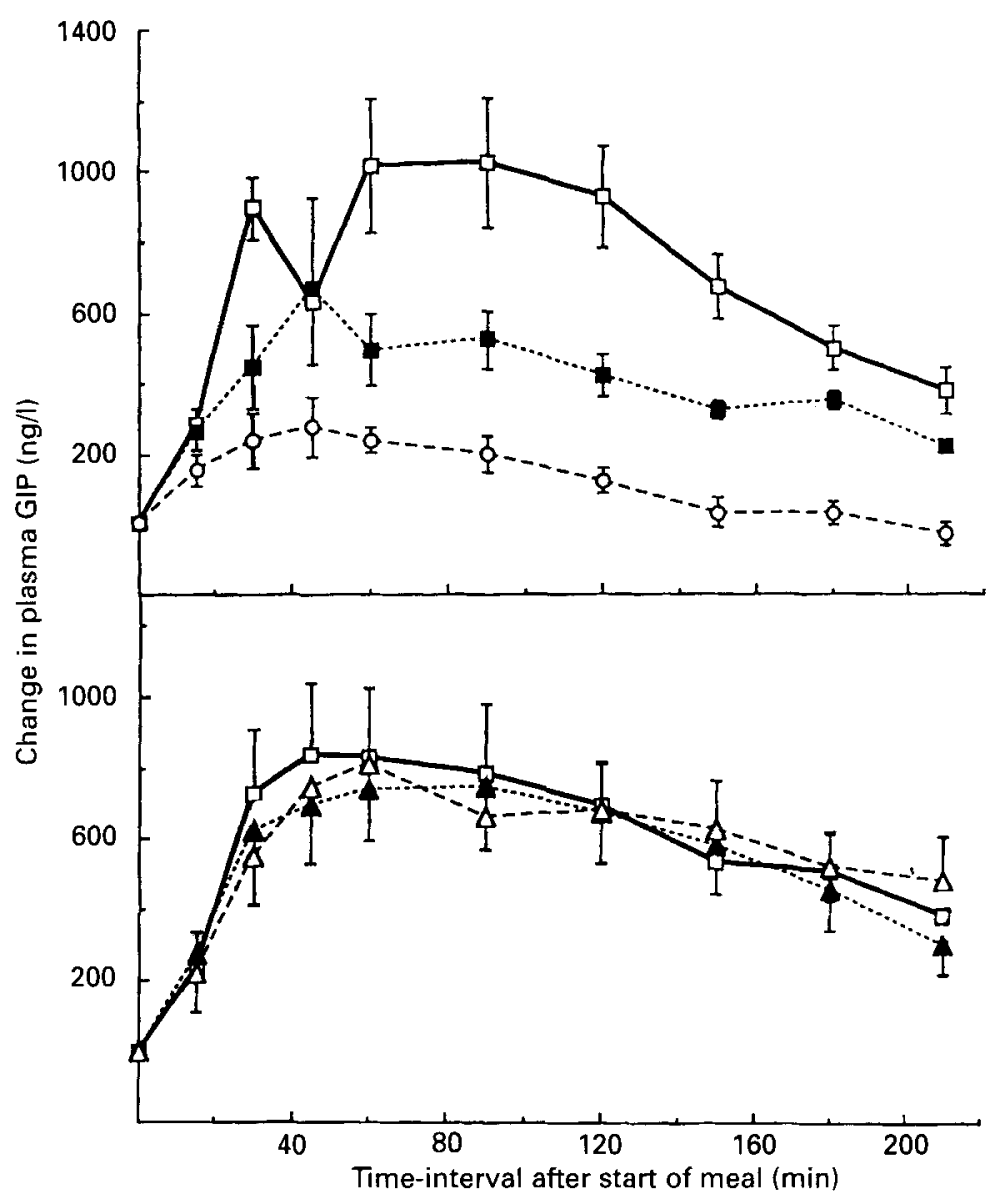

Fig. 2. Plasma gastric inhibitory polypeptide (GIP) concentrations following a high-fat test meal alone ( $\square-\square$ ) or supplemented with $10 \mathrm{~g}$ guar gum $(\mathbf{\square}-\mathbf{\square})$, cholestyramine $(\mathrm{O}-\mathrm{O})$, sugar-beet fibre $(\triangle-\triangle)$ or wheat bran $(\boldsymbol{\Delta}-\mathbf{\Delta})$ in eight healthy volunteers. Points are means with their standard errors represented by vertical bars. For details of procedures, see pp. $492-494$.

Circulating postprandial triacylglycerol, GIP and bile acid levels showed quite a large interindividual variation. However, a significant positive correlation was found between subjects' customary fat consumption expressed as percentage total energy intake and postprandial integrated triacylglycerol and bile acid responses $(r 0.40$ and 0.52 for triacylglycerol and bile acid responses respectively; $P<0.01$ ).

Supplementation with both guar gum and cholestyramine significantly lowered plasma bile acid concentrations (Fig. 1) and the incremental AUC (0-210 min) for bile acids were also significantly reduced with both guar gum and cholestyramine $(P<0 \cdot 01$, Table 2$)$.

Postprandial plasma GIP levels were significantly reduced following both guar gum and cholestyramine (Fig. 2), the attenuation being more marked for the cholestyramine. The incremental AUC for GIP $(0-210 \mathrm{~min})$ was also significantly reduced $(P<0.01)$ in the guar gum- and cholestyramine-supplemented meals compared with the control meal (Table 2).

The rise in circulating triacylglycerol levels following the guar gum- or cholestyraminesupplemented meals was delayed in the first $2 \mathrm{~h}$ following meal ingestion, compared with the control meal (Fig. 3). Mean peak plasma triacylglycerol levels were achieved at $90 \mathrm{~min}$ 


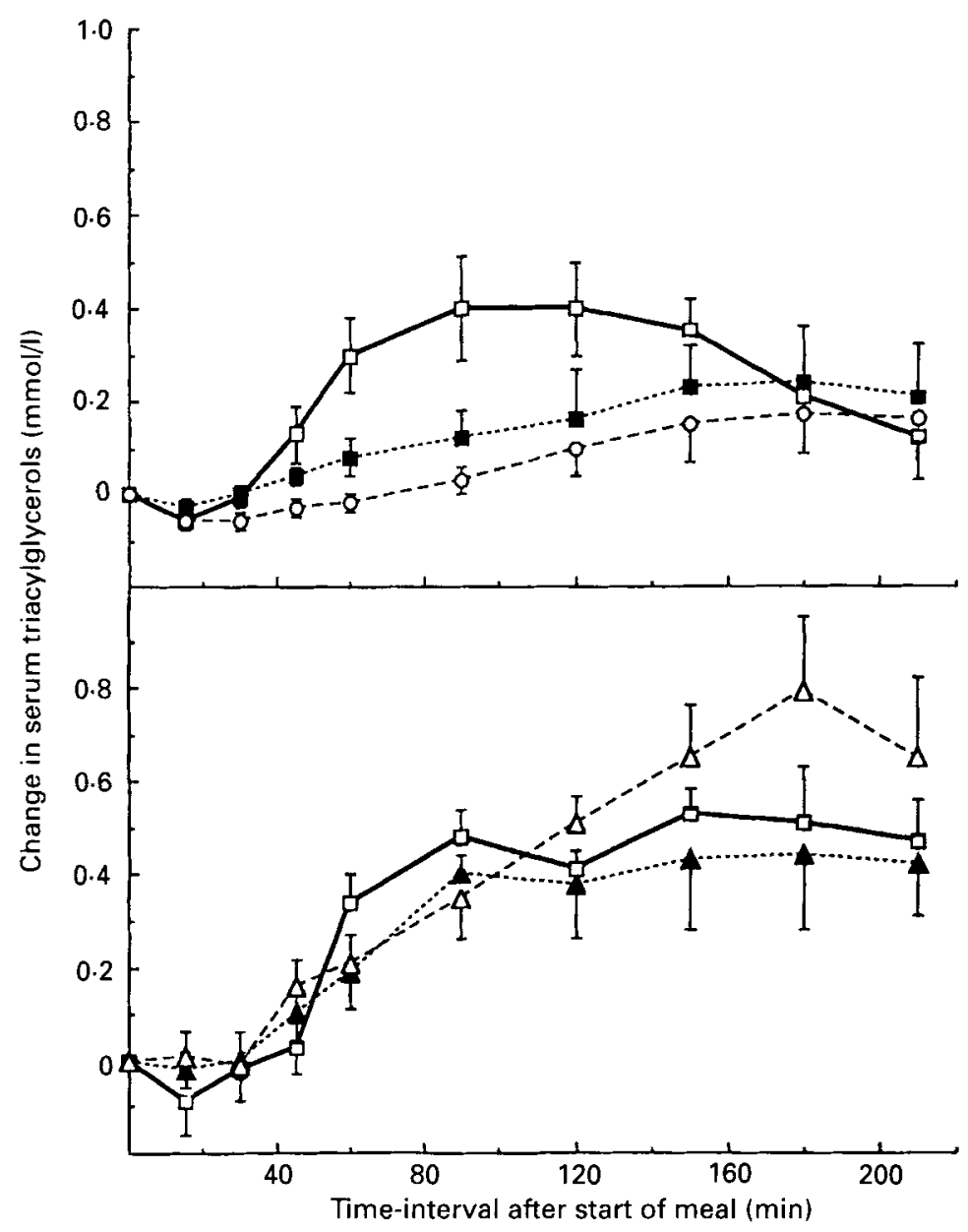

Fig. 3. Serum triacylglycerol concentrations following a high-fat test meal alone $(\square-\square)$ or supplemented with $10 \mathrm{~g}$ guar gum $(\mathbf{C}-\mathbf{D})$, cholestyramine $(O-O)$, sugar-beet fibre $(\triangle-\triangle)$ or wheat bran $(\boldsymbol{\Delta}-\mathbf{\Delta})$ in eight healthy volunteers. Points are means with their standard errors represented by vertical bars. For details of procedures, see pp. $492-494$.

following the control meal compared with 180 min for the guar gum- and cholestyraminesupplemented meals. The incremental AUC (0-210 min) was also significantly reduced $(P<0.01)$ following the cholestyramine- and guar gum-supplemented meals.

In the early part of the study mean peak paracetamol levels were higher in the guar gumsupplemented meal than in the control and peak levels observed earlier, at 15 min for guar gum compared with 45 min for the control meal (Fig. 4), suggesting that liquid gastric emptying is accelerated in the guar gum-supplemented meal.

\section{Study B. SBF and wheat bran supplementation}

Analysis of variance failed to demonstrate any significant effect of SBF or bran supplementation on postprandial circulating total bile acids, GIP, paracetamol or triacylglycerol levels (Figs. 1-4). There was, however, a tendency for the rise in circulating triacylglycerol levels to be delayed following the SBF-supplemented meal (Fig. 3) with mean peak plasma triacylglycerol levels occurring at $180 \mathrm{~min}$ following the SBF- 


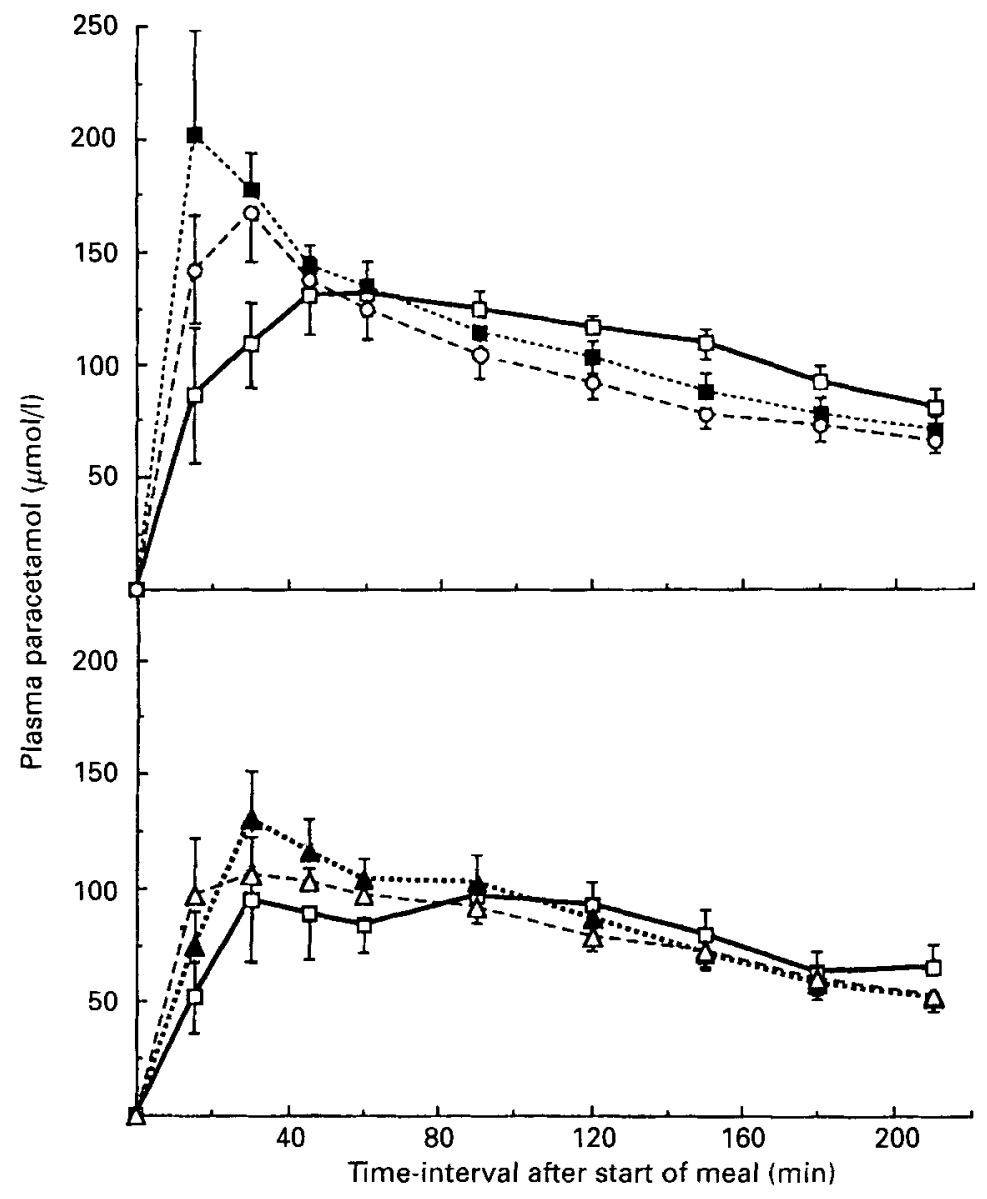

Fig. 4. Plasma paracetamol concentrations following a high-fat test meal alone $(\square-\square)$ or supplemented with $10 \mathrm{~g}$ guar gum $\left(\boldsymbol{\square}^{-} \boldsymbol{\square}\right)$, cholestyramine $\left(\mathrm{O}^{-} \mathrm{O}\right)$, sugar-beet fibre $\left(\Delta^{-} \triangle\right)$ or wheat bran $\left(\boldsymbol{\Delta}^{-} \boldsymbol{\Delta}\right)$ in eight healthy volunteers. Points are means with their standard errors represented by vertical bars. For details of procedures, see pp. $492-494$.

Table 3. In vitro Glycocholic acid binding to the soluble and insoluble fractions of various non-starch polysaccharide preparations and to cholestyramine*

(Mean values with their standard errors for six determinations)

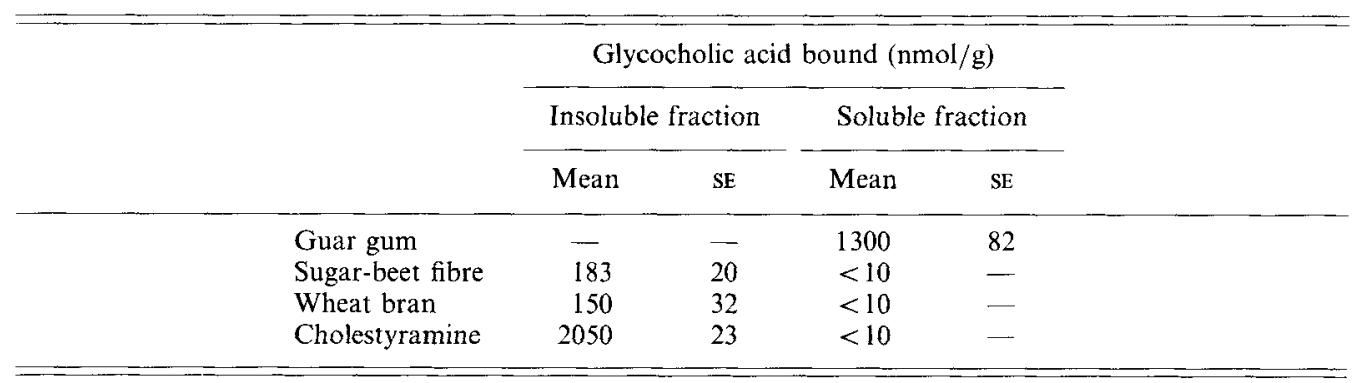

* For details of procedures, see pp. $492-494$. 
supplemented meal. Neither bran nor SBF affected the incremental AUC (0-210 min) for any of the variables measured (Table 2).

\section{In vitro bile acid binding}

Binding of $\left[{ }^{14} \mathrm{C}\right]$ glycocholic acid to the insoluble and soluble NSP fractions is shown in Table 3. The insoluble fractions of SBF and wheat bran bound small quantities of glycocholate, but binding to the insoluble fractions was 10 -fold lower in the NSP than in the cholestyramine preparations. The bile acids in the supernatant fractions of the wheat bran, SBF and cholestyramine preparations were totally dialysable through a $10 \mathrm{kDa}$ molecular weight dialysis membrane, indicating that there was no binding of bile acids to high-molecular-weight soluble fractions. The guar gum preparation contained no insoluble NSP. However, glycocholate was strongly adsorbed to the soluble NSP in the guar gum preparation.

\section{DISCUSSION}

A positive correlation was observed in the present study between subjects' customary fat consumption and postprandial bile acid and triacylglycerol levels. Deschodt-Lanckman et al. (1971) have shown that pancreatic lipase (EC 3.1.1.3) activity in the rat is stimulated by a high-fat diet. Subjects customarily eating a lower-fat diet, therefore, might have a decreased rate of triacylglycerol absorption due to lower lipase activity and bile salt secretion. We have previously shown a decrease in both postprandial triacylglycerol and GIP levels following oral fat after subjects consumed a low-fat diet for 1 month (Morgan et al. 1988). The lack of any correlation in the present study between fat intake and GIP secretion may have been due to the subjects' narrower range of fat intakes in the present study compared with the previous one.

In the present study postprandial circulating bile acid levels were markedly attenuated by the addition of guar gum or cholestyramine to the test meals but were unaffected by wheat bran or SBF. Hansen et al. (1983) have previously demonstrated that larger amounts ( $15 \mathrm{~g})$ of guar gum supplementation lowered postprandial circulating bile acids following an $837 \mathrm{~kJ}$ liquid mixed meal. The effect of guar gum supplementation on bile acids is much more pronounced in the present study, presumably due to the higher fat content of the test meal. Intestinal reabsorption of bile salts in man is $96-98 \%$ efficient (Heaton, 1976). Given normal hepatic function, the major determinant of serum bile acid levels in man is their rate of intestinal absorption (La Russo et al. 1978) which is, in turn, influenced by the adsorption of bile acids to food components within the gastrointestinal tract. It was expected, therefore, that the ability of cholestyramine and the NSP sources studied to bind bile acids in vitro would reflect their in vivo effects on postprandial circulating bile acids.

Glycocholate was strongly adsorbed in vitro to both guar gum and cholestyramine, but only weakly adsorbed to SBF and wheat bran. The values for in vitro bile acid binding to wheat bran and cholestyramine are similar to those reported by Quin et al. (1991) using similar methodology. The low binding of glycocholate to SBF was consistent with a previous report of low sodium taurocholate in vitro binding to sugar-beet pulp (Kritchevsky $\&$ Story, 1974). The absence of any detectable binding in the soluble fraction of SBF was unexpected in view of the high levels of pectic substances in SBF but consistent with our in vivo studies, which failed to show any effect of SBF supplementation on circulating bile acid levels. Addition of citrus pectin to the diet has been shown to increase faecal bile acid excretion in man (Kay \& Truswell, 1977 a; Bosaeus et al. 1986), presumably by bile acid adsorption, and this is considered the likely mechanism by which pectin exerts its hypocholesterolaemic effect. This is in contrast to wheat bran supplementation, which is generally without effect on faecal bile acid excretion or circulating cholesterol levels 
(Bosaeus et al. 1986; Kay \& Truswell, 1977 b). Consistent with our in vitro findings, Quin et al. (1991) have found that the in vitro bile acid binding of both soluble and insoluble fractions of apple fibre (a rich source of pectin) was low. The extent of in vitro bile acid binding to NSP is dependent on the assay conditions used and may not reflect those occurring physiologically. Nevertheless, pectin, an acidic NSP, is ionized in the mildly alkaline environment of the small intestine and, therefore, might not be expected to bind bile acids in vivo. Pectin polysaccharides of sugar beet origin also differ structurally from citrus pectin in terms of their degree of cross-linking within the cell wall matrix, side-chain composition and solubility under more physiological conditions (Selvendran \& Robertson, 1990). These differences may account for observed differences in bile acid binding.

The findings of the present study, therefore, do not support the hypothesis that the hypocholesterolaemic action of SBF in man is due to the sequestration of intestinal bile salts and subsequent interruption of the enterohepatic bile acid circulation. These conclusions have been reinforced by subsequent studies (L. Morgan, J. Tredger, J. Travis and J. Wright, unpublished results) in which a pectin-rich fraction of SBF failed to show significant effects on either in vitro bile acid binding or in vivo postprandial bile acid levels.

Supplementation with guar gum and cholestyramine delayed and attenuated the rise in plasma triacylglycerols following the meal and a similar trend was apparent following supplementation with SBF. Diminished GIP responses were also seen following the cholestyramine- and guar gum-supplemented meals, but no significant differences in GIP secretion were observed following SBF supplementation. GIP secretion is dependent on the absorption of fat across the gut mucosa (Creutzfeldt, 1979) and this attenuated GIP response is consistent with the delayed absorption of triacylglycerols following guar gum and cholestyramine. Under certain circumstances guar gum supplementation can cause a delay in gastric emptying (Wilmshurst \& Crawley, 1980) which could contribute to the delay in triacylglycerol absorption. However, in the present study gastric emptying was accelerated by the addition of guar gum, as assessed by circulating paracetamol levels. The effect of guar gum supplementation on gastric emptying is dependent on the type and size of meal consumed and other studies have shown gastric emptying rates to be unaltered (Rainbird et al. 1982) or slightly accelerated (Tredger et al. 1979, 1984) following guar gum supplementation. Other mechanisms, therefore, must be responsible for the changes observed. The sequestration of bile salts by cholestyramine and guar gum would make them unavailable for micelle formation and consequently the amount of lipid solubilized in the intestine could be decreased, leading to reduced lipid absorption (Gallaher \& Schneeman, 1986). Interference with bulk phase diffusion could also occur, especially with a viscous fibre such as guar gum (Vahouny et al. 1980). In addition, guar gum has been reported to inhibit the activity of pancreatic lipase (Isackson et al. 1983), thus slowing down the rate of lipid absorption. The failure of bran supplementation to modify postprandial triacylglycerol or GIP levels is consistent with its inability to affect circulating postprandial bile acids and its lack of hypocholesterolaemic action. In general, those dietary components which reduce the rate of triacylglycerol absorption have a similar effect on dietary cholesterol absorption (Vahouny et al. 1980), thereby contributing to their hypocholesterolaemic action.

The present study supports the hypothesis that the hypocholesterolaemic action of guar gum is largely mediated via interruption of the enterohepatic bile acid circulation. However, other mechanisms, such as those described previously, cannot be excluded. In addition, guar gum supplementation reduces postprandial insulin secretion (Jenkins et al. 1977; Morgan et al. 1978a) and this may contribute to the reduction in circulating cholesterol, as insulin has been implicated in increasing rates of hepatic cholesterogenesis (Vasconcelos et al. 1989). 
In conclusion, the present study demonstrates that measurement of postprandial circulating bile acids enabled an indirect measure to be made of bile acid binding to NSP in vivo. Although other mechanisms cannot be excluded, the hypocholesterolaemic action of guar gum is, like cholestyramine, probably mediated via its sequestering effects on bile acids. However, the findings from the present study do not support the hypothesis that the hypocholesterolaemic action of SBF is due to this mechanism, and its mode of action, therefore, must remain speculative. NSP are very heterogeneous both physically and chemically and, therefore, caution must be exercised in attributing a single mechanism of action for their hypocholesterolaemic effects which is universally applicable.

The authors are grateful to British Sugar for their financial support and for provision of sugar-beet fibre and to Rybar Laboratories Ltd, who kindly supplied the guar gum.

\section{REFERENCES}

Betteridge, D. J. (1989). Lipids, diabetes and vascular disease: the time to act. Diabetic Medicine 6, 195-218.

Bosaeus, I., Carlsson, N.-G., Sandberg, A.-S. \& Andersson, H. (1986). Effect of wheat bran and pectin on bile acid and cholesterol excretion in ileostomy patients. Human Nutrition and Clinical Nutrition 40C, 429-440.

Creutzfeldt, W. (1979). The incretin concept today. Diabetologia 16, 75-85.

Deschodt-Lanckman, M., Robberecht, P., Camus, J. \& Cristophe, J. (1971). Short-term adaptation of pancreatic hydrolases to nutritional and physiological stimuli in adult rats. Biochemie 53, 789-796.

Eastwood, M. A. \& Hamilton, D. (1968). Studies on the adsorption of bile salts to non-absorbed components of the diet. Biochimica et Biophysica Acta 152, 165-173.

Farrell, D. J., Girle, L. \& Arthur, J. (1978). Effects of dietary fibre on the apparent digestibility of major food components and on blood lipids in men. Australian Journal of Experimental Biology and Medical Science 56, 469-479.

Gallaher, D. \& Schneeman, B. (1986). Intestinal interaction of bile acids, phospholipids, dietary fibers and cholestyramine. American Journal of Physiology 250, G420-426.

Hagander, B., Asp, N.-G., Efendic, S., Nilsson-Ehle, P. \& Scherstern, B. (1988). Dietary fiber decreases fasting blood glucose levels and plasma LDL concentration in non-insulin-dependent diabetes mellitus patients. American Journal of Clinical Nutrition 47, 852-858.

Hallworth, M. J. (1983). Enzymatic method for acetaminophen adapted to a centrifugal analyser. Clinical Chemistry 29, 2123-2124.

Hansen, W. E., Maurer, H., Vollmar, J. \& Brauning, C. (1983). Guar gum and bile: effects on postprandial gallbladder contraction and on serum bile acids in man. Hepato-gastroenterology 30, 131-133.

Hashim, S. A. \& van Itallie, T. B. (1965). Cholestyramine resin therapy for hypercholesterolaemia. Clinical and metabolic studies. Journal of the American Medical Association 192, 289-293.

Heaton, K. W. (1976). Clinical aspects of bile acid metabolism. In Recent Advances in Gastroenterology, pp. 200-230 [I. A. D. Bouchier, editor]. London: Churchill-Livingstone.

Isackson, G., Asp, N.-G. \& Ihse, I. (1983). The effect of dietary fibre on pancreatic enzyme activities of ileostomy evacuates and on excretion of fat and nitrogen in the rat. Scandinavian Journal of Gastroenterology 18, 417-423.

Jenkins, D. J. A., Leeds, A. R., Newton, C. \& Cumming, J. H. (1975). The effect of pectin, guar gum and wheat fibre on serum cholesterol. Lancet ii, 1116-1119.

Jenkins, D. J. A., Taylor, R. H., Nineham, R., Goff, D. V., Bloom, S. R., Sarson, D. \& Alberti, K. G. M. M. (1977). Combined use of guar and acarbose in reduction of post-prandial glycaemia. Lancet ii, 924-927.

Kay, R. M. \& Truswell, A. S. (1977a). Effect of citrus pectin on blood lipids and fecal steroid excretion in man. American Journal of Clinical Nutrition 30, 171-175.

Kay, R. M. \& Truswell, A. S. $(1977 b)$. The effect of wheat fibre on plasma lipids and faecal steroid excretion in man. British Joumal of Nutrition 37, 227-235.

Khan, A. R., Khan, G. Y., Mitchel, A. \& Qadeer, M. A. (1981). Effect of guar gum on blood lipids. American Journal of Clinical Nutrition 34, 824-829.

Kritchevsky, D. \& Story, J. A. (1974). Binding of bile salts in vitro by non-nutritive fiber. Journal of Nutrition 104, $458-462$.

Kritchevsky, D., Vahouny, G. V. \& Story, J. A. (1986). Dietary fibre and lipid metabolism. In Proceedings of the XIIIth International Congress of Nutrition, 1985, pp. 175-181 [T. G. Taylor and W. K. Jenkins, editors]. London: John Libbey.

La Russo, N. F., Hoffman, N. E., Korman, M. G., Hoffmann, A. F. \& Cowen, A. E. (1978). Determinants of fasting and postprandial serum bile acid levels in healthy man. Digestive Diseases 23, 385-391.

Moore, D. J., White, F. J., Flatt, P. R. \& Parke, D. V. (1985). Beneficial short-term effects of unprocessed wheat bran on lipid and glucose metabolism in man. Human Nutrition, Clinical Nutrition 39C, 63-67. 
Morgan, L. M., Goulder, T. J., Tsiolakis, D., Marks, V. \& Alberti, K. G. M. M. (1978a). The effect of unabsorbable carbohydrate on gut hormones: modification of post-prandial GIP secretion by guar. Diabetologia 17, 85-89.

Morgan, L. M., Morris, B. A. \& Marks, V. (1978 b). Radioimmunoassay of gastric inhibitory polypeptide. Annals of Clinical Biochemistry 15, 172-177.

Morgan, L. M., Tredger, J. A., Hampton, S. M., French, A. P., Peake, J. C. F. \& Marks, V. (1988). The effect of dietary modification and hyperglycaemia on gastric emptying and gastric inhibitory polypeptide (GIP) secretion. British Journal of Nutrition 60, 29-37.

Paul, A. A. \& Southgate, D. A. T. (1978). Mc Cance and Widdowson's The Composition of Foods, 4th ed. London: H.M. Stationery Office.

Penagini, R., Velio, P., Vigorelli, R., Bozzani, A., Castagnone, D., Ranzi, T. \& Biacho, P. A. (1986). The effect of dietary guar on serum cholesterol intestinal transit and fecal output in man. American Journal of Gastroenterology 81, 123-129.

Quin, G., Flynn, A. \& Morrissey, P. A. (1991). In vitro binding of bile acids to dietary fibre. Proceedings of the Nutrition Society 50, 206A.

Rainbird, A. L., Low, A. G. \& Sambrook, I. E. (1982). Lack of effect of guar gum on gastric emptying in pigs. Proceedings of the Nutrition Society 39, 42A.

Selvendran, R. R. \& Robertson, J. A. (1990). The chemistry of dietary fibre - an holistic view of the cell wall matrix. In Dietary Fibre: Chemical and Biological Aspects, pp. 27-43 [D. A. T. Southgate, K. Waldron, I. T. Johnson and G. R. Fenwick, editors]. Cambridge: Royal Society of Chemistry.

Starkey, B. J. \& Marks, V. (1982). Determination of bile acids in serum - a comparison of RIA with an enzymatic fluorimetric method. Clinica Chimica Acta 119, 165-177.

Story, J. A. \& Kritchevsky, D. (1976). Comparison of the binding of various bile acids and bile salts in vitro by several types of fiber. Journal of Nutrition 106, 1292-1294.

Topping, D., Illman, R. J., Dowling, K. \& Trimble, R. P. (1990). Mechanisms whereby fibre could lower plasma cholesterol. In Dietary Fibre: Chemical and Biological Aspects, pp. 300-304 [D. A. T. Southgate, K. Waldron, I. T. Johnson and G. R. Fenwick, editors]. Cambridge: Royal Society of Chemistry.

Tredger, J. A., Morgan, L. M., Peake, J. \& Marks, V. (1984). Effect of guar gum on the rate of gastric emptying in healthy human subjects. Regulatory Peptides $\mathbf{9}, 350$.

Tredger, J. A., Morgan, L. M., Travis, J. \& Marks, V. (1991). The effects of guar gum, sugar beet fibre and wheat bran supplementation on serum lipoprotein levels in normocholesterolaemic volunteers. Journal of Human Nutrition and Dietetics 4, 59-67.

Tredger, J. A., Wright, J. \& Marks, V. (1979). The effect of guar gum on blood alcohol levels following gin and tonic consumption. Proceedings of the Nutrition Society 38,70A.

Vahouny, G. V., Roy, T., Gallo, L. L., Story, J. A., Kritchevsky, D. \& Cassidy, M. (1980). Dietary fibers. III. Effects of chronic intake on cholesterol absorption and metabolism in the rat. American Journal of Clinical Nutrition 33, 2182-2191.

Vasconcelos, P. R. L., Kettlewell, M. G. W., Gibbons, G. F. \& Williamson, D. H. (1989). Increased rates of hepatic cholesterogenesis and fatty acid synthesis in septic rats in vivo: evidence for the possible involvement of insulin. Clinical Science 16, 205-211.

Wahlefield, A. W. (1974). Triglycerides, determination after enzymatic hydrolysis. In Methods of Enzymatic Analysis, 2nd ed., p. 1831. New York and London: Verlag Chemie Weinheim and Academic Press.

Wilmshurst, P. \& Crawley, J. C. W. (1980). The measurement of gastric transit time in obese subjects using ${ }^{22} \mathrm{Na}$ and the effects of energy content and guar gum on gastric emptying and satiety. British Journal of Nutrition 44. $1-6$. 